January 1960 to February 1970 . Even so, because of the rapidly developing nature of the subject, the authors have had to be selective in the areas covered. As authorities in the field, they have, however, chosen judiciously. The review begins with a brief survey of the geometry of the molecules of compounds which form thermotropic liquid crystals, and moves on to a useful review of the very active areas concerning polymorphism of liquid crystals and theories of liquid crystal structure. This is followed by a survey of recent work on certain physical properties and physical methods of studying thermotropic liquid crystals, attention being paid mainly to effects of external forces and fields, thermodynamic behaviour, nuclear magnetic resonance spectroscopy, electron paramagnetic resonance spectroscopy, Mössbauer effects, light scattering and spin-lattice relaxation. Infrared and Raman spectroscopy receive only brief mention, as do some other physical properties such as viscosity, ultrasonics, Brillouin scattering, positron annihilation and birefringence.

A most attractive feature of the review is that it ends with an eleven page section on lyotropic liquid crystals, that is, on liquid crystals formed by amphiphilic compounds and solvents. Too often the so-called thermotropic and lyotropic classes of liquid crystal are divorced from one another in reviews and texts on liquid crystals, whereas ideally the two should be considered side by side so that developments in one area may stimulate progress in the other. This section is most informative, and the diagrams of the structures of the various lyotropic mesophases are particularly useful.

This hard backed version of the original article is well written and attractive. in its form and presentation. It should be stressed, however, that it is not a textbook on liquid crystals, and that because it is a selective review of particular areas, some topics have not been covered. One of these is the technological applications of liquid crystals. The book will therefore appeal mainly to those engaged on pure research on liquid crystal systems.

G. W. Gray

\section{Nuclear Apple}

The Nuclear Apple: Discoveries in Fundamental Physics. By P. T. Mathews. Pp. viii +150 . (Chatto and Windus: London, 1971.) £2.00.

IN this book, Professor Matthews describes developments in fundamental physics which have led to our present state of understanding and lack of understanding of sub-nuclear or elementary particle physics. The book is aimed at the non-specialist and the language is simple, direct, and generally free from technical jargon.

Both the title and the sub-title are something of a puzzle, since many topics in fundamental physics are omitted or given only passing reference, and the physics of nuclei is dismissed with the observation that in a typical nucleus "the situation is far too complicated to be sorted out in any detail". However, such topics as the nature of the strong and weak interactions and the classification of particles are discussed with insight and vivid analogy. Most important, perhaps, are the pages devoted to discussion of the function of physics, its relation to mathematics, and of the role of observation and prediction in a quantum theory.

From a pedagogical point of view, it seems a pity that the symbol $h$ has been used to represent $h / 2 \pi$ so that the spin of the electron appears as $\frac{1}{2} h$ and the energy of a photon is written as $E=h \omega$. Also, a surprisingly concrete picture is given of the orbital motion of an electron in an atom and of the spin-angular momentum.

The comments of a reviewer are to a large extent irrelevant for a book of this type. What matters is the response of the non-specialist reader. It is to be hoped that this book will find its way into many school libraries and that it will make the sort of impact that the works of Jeans, Eddington, and Andrade have made on previous generations.

DAPHNE F. JACKSON

\section{Electrical Machines}

Linear Electric Motors. By E. R. Laithwaite. Pp. 101. (Mills and Boon: London, October 1971.) $£ 2.50$.

Professor LaIthwaIte is a superb popularizer and is incapable of writing a dull book; this is no exception. Linear Electric Motors is a short book (101 pages), which deals with a wide range of topics. It is thought-provoking, but I am forced to ask, who Professor Laithwaite had in mind when he wrote it?" In spite of the apparent simplicity of his writing, Professor Laithwaite implicitly assumeș a substantial knowledge of conventional electrical machines, so that the inexpert reader who wants a broad-brush treatment of linear motors would find himself in deep water at times. If he is prepared to skip the profound passages, which are sketchy because of the brevity of the book, he will get a fair picture of what can be done with linear machines and a challenging picture of where imaginative topological tricks might lead electrical machines. He will be less well served in discussion of what a linear machine cannot do, which may be his reason for reading the book!

On the other hand, the book draws so extensively on the author's more scholarly "Induction Machines for Special Purposes" (Newnes, 1966) that the informed reader has a strong sense of "déja vu" and, on checking, finds that many of the diagrams (and many of the ideas) previously appeared in that book, but with a much more thorough explanation. Yet the earlier book is not quoted in the main text and only appears as item 13 in the references. It is hard to believe the statement on the cover that the work "contains the most complete and up-to-date information ... so far published"; for those "skilled in the art", the earlier work is more complete and essentially up-todate, and so is to be preferred.

\section{E. J. Davies}

\section{Diffraction from Gases}

Electron Diffraction in Gases. By Michael I. Davis. Pp. $x+181$. (Marcel Dekker: New York, 1971.) \$12.50.

SINCE our boyhood at Latymer Upper School, Michael Davis and I, entirely by coincidence, have found our paths crossing repeatedly as researchers in gas-phase electron diffraction. Workers in the field number no more than about fifty, worldwide, in spite of the extremely valuable information about molecular geometry which the method produces. Davis traces the origins of the specialized modern techniques to the equipment and philosophies of the Michigan and Norwegian groups of the 1950 s. Perhaps he underrates the contributions of the Russian and Japanese groups, but most students in the field still make their pilgrimages to Ann Arbor and Oslo. His experience with Norwegian and American groups equips him well to write this book-the first devoted wholly to the subject. The book is oriented towards the (graduate) student; it will serve as an excellent introduction to the method, but lacks illustration of its applications and contains the vagaries often associated with students' books. One drawback to this approach is that many concepts and formulae must be stated without proper justification or derivation; this certainly shortens the book, but one is in danger of producing graduates who, like some of Asimov's inhabitants of the future, are unable to do more than follow the rituals laid down by their predecessors. But taking into account the pressures placed by publishers on authors these days-to be brief yet still comprehensive-I am sure this would have been just the sort of book I would have written myself had I not been deflected from the task by a move from Glasgow to Manchester. I shall certainly recommend the book to my specialist students. BRIAN BEAGLEY 